\title{
Clinical and therapeutic features of acute cholecystitis in diabetic patients
}

\author{
DRAGOS SERBAN ${ }^{1,2}$, SIMONA ANDREEA BALASESCU ${ }^{1}$, CATALIN ALIUS ${ }^{1}$, CRISTIAN BALALAU ${ }^{2,3}$, \\ ALEXANDRU DAN SABAU ${ }^{4}$, CRISTINEL DUMITRU BADIU ${ }^{2}$, BOGDAN SOCEA ${ }^{2,3}$, ANDRA MARIA TROTEA ${ }^{2}$, \\ ANA MARIA DASCALU ${ }^{2}$, ION MOTOFEI ${ }^{2,3}$, VALERIU ARDELEANU ${ }^{5-7}$, RADU IULIAN SPATARU $^{2,8}$, \\ DAN SABAU ${ }^{4}$ and GABRIEL CATALIN SMARANDACHE ${ }^{1,2}$
}

${ }^{1}$ 4th Surgery Department, Emergency University Hospital Bucharest, 050098 Bucharest; ${ }^{2}$ Faculty of Medicine, University of Medicine and Pharmacy 'Carol Davila' Bucharest, 020021 Bucharest; ${ }^{3}$ Department of Surgery, 'Sf. Pantelimon’ Emergency Hospital, 021659 Bucharest; ${ }^{4}$ 3rd Clinical Department, Faculty of Medicine, 'Lucian Blaga' University Sibiu, 550169 Sibiu; ${ }^{5}$ The Faculty of Medicine, Doctoral School, 'Ovidius' University, 900527 Constanta; ${ }^{6}$ Department of Surgery, General Hospital CFR, 800223 Galati;

${ }^{7}$ Department of Plastic Surgery, Arestetic Clinic, BR4A, 800108 Galati; ${ }^{8}$ Department of Pediatric Surgery, Emergency Clinic Hospital for Children 'Marie S. Curie', 077120 Bucharest, Romania

Received February 1, 2021; Accepted March 3, 2021

DOI: $10.3892 / \mathrm{etm} .2021 .10190$

\begin{abstract}
The present study aimed to compare the clinical, paraclinical, intraoperative findings, and postoperative complications in acute cholecystitis in diabetic patients vs. non-diabetic patients. A 2-year retrospective study was performed on the patients who underwent emergency cholecystectomy for acute cholecystitis between 2017 and 2019 at the 4th Department of Surgery, Emergency University Hospital Bucharest. The diabetic subgroup numbered 46 eligible patients and the non-diabetic one 287 patients. Demographics, the severity of the clinical forms, biological variables (including white cell count, urea, creatinine, coagulation and liver function tests) comorbidity status, surgical approach, postoperative complications, and hospital stay were analyzed. Statistical analyses were performed to assess comparative results between the aforementioned data (SPSS V 13.0). The CCI and ASA risk classes were increased in the diabetic group, with $34.78 \%$ of patients having 3 or more associated comorbidities. No statistically significant associations were demonstrated between diabetes and the severity of the cholecystitis and risk for conversion. Postoperatively both minor complications such as surgical site infections and major cardiovascular events were more common in the diabetic subgroup $(\mathrm{P}=0.0254)$, well associated with the preoperative status and baseline cardiovascular comorbidities.
\end{abstract}

Correspondence to: Dr Simona Andreea Balasescu, 4th Surgery Department, Emergency University Hospital Bucharest, Splaiul Independentei 169, sector 5, 050098 Bucharest, Romania E-mail: simona.a.balasescu@gmail.com

Key words: acute cholecystitis, diabetes mellitus, cholelithiasis, laparoscopic cholecystectomy
Laparoscopic cholecystectomy is a safe procedure for diabetic patients, which can provide the best outcomes, by decreasing the risks of surgical wounds. Attentive perioperative care and good glycemic control must be provided to minimize the risk of complications.

\section{Introduction}

With a rising prevalence of diabetes mellitus (DM) in the worldwide population, increased awareness of the multifaceted clinical spectra of biliary conditions in diabetic patients could lead to early diagnosis and improved outcomes (1). Contrary to the famous quote of William Mayo stating that 'there is no innocent gallstone', recent studies on the natural history of cholelithiasis indicate that less than one-third of the patients having gallstones will eventually become symptomatic (2-4). Although the same observation applies in patients suffering from DM, these tend to develop more severe complications, have longer hospital stays, and higher fatality rates (5). As a result, before the era of evidence-based medicine, for numerous generations of surgeons the logic-driven temptation to recommend prophylactic cholecystectomies in this category of patients became a perpetuated paradigm (6).

Even today there are numerous controversial aspects related to the diagnosis and management of gallstones and acute cholecystitis in diabetic patients in whom classical symptoms have different clinical connotations. These are attributed to diabetic neuropathy, impaired host response to infection, and various structural tissue damage caused by long term exposure to hyperglycemia (7). Although empirical evidence reported by surgeons and physicians over time suggested that special care should be taken when managing diabetic patients with biliary conditions there are no widely accepted guidelines on the matter. Perhaps this is due to the great variability in clinical presentations and response to treatment. 
Attempting standardization of assessment and establishment of prognostic factors to support clinical decisions for acute cholecystitis in general, the Japanese Society of Gastroenterology published the Tokyo Guidelines in 2013, revised later in 2018 (TG 13/18) (8) which were used in the present for various stratifications of the cohorts.

The present study aimed to compare the clinical, paraclinical, intraoperative findings, and postoperative complications in acute cholecystitis in diabetic vs. non-diabetic patients.

\section{Materials and methods}

Study design. A 2-year retrospective study was performed on the patients who underwent emergency cholecystectomy for acute cholecystitis between January 2017 and December 2019 at the 4th Department of Surgery, Emergency University Hospital, Bucharest, Romania. A total of 333 patients, aged between 18-91 years were identified. The study group was divided into two subgroups based on the presence of DM. The diabetic subgroup numbered 46 eligible patients and the non-diabetic one 287 patients. Data were collected from observation charts and postoperative notes.

The inclusion criteria for the study consisted of: i) Emergency admission for acute cholecystitis followed by cholecystectomy later than $72 \mathrm{~h}$ from the admission; and ii) accurate documentation of the clinical and paraclinical data pertaining to the calculation of the Tokyo criteria, American Society of Anesthesiologists (ASA) Physical Status Classification (9) and Charlson Comorbidity Index (CCI) (10).

Exclusion criteria were: i) Associated pancreatitis or ii) any malignancy (Table I).

Data comparison and statistical analysis. Demographics, the severity of the clinical forms, biological variables [white cell count (WCC), urea, creatinine, coagulation, and liver function tests (LFTs)] comorbidity status, surgical approach, postoperative complications, and hospital stay were analyzed.

Statistical analyses were performed to assess comparative results between the aforementioned data. For descriptive analysis, the medians, means, and standard deviations were used. Pearson chi-square or Fisher exact test (if the number of observations in the cells was <5) and ANOVA test were used to evaluate associations between different variables. Relative risk and odds ratio for diabetic vs. non-diabetic patients were calculated for the following outcomes: major complications, surgery-related complications, in-hospital infection (SPPSS 13.0 version; SPSS, Inc.).

The study was released from the formal consent of the ethical board due to its retrospective nature.

\section{Results}

General data and comorbidities. Among the 46 diabetic patients, the sex ratio was almost equal, while in the control group there was a definite predominance for the female sex, with an F:M ratio of 3:1 $(\mathrm{P}<0.001)$ There were no significant differences between the diabetic and the non-diabetic group regarding the early/delayed presentation to Emergency Room. The CCI and ASA risk classes were increased in the diabetic group, with $34.78 \%$ of patients having 3 or more associated comorbidities. A statistically significant association was identified between the presence of DM and arterial hypertension $(\mathrm{P}<0.001)$ and ischemic cardiopathy $(\mathrm{P}=0.0043)$ (Table II).

Preoperative assessment included clinical and paraclinical exploration. Ultrasound examinations confirmed the presence of gallbladder stones and evaluated the thickness of the gallbladder wall: Double contour and pericholecystic fluid were markers for severe local inflammation (Table III).

The incidence of the severe cases in diabetic patients was higher than the value of that recorded in non-diabetics, but the result was not statistically significant $(\mathrm{P}=0.058$; Table III). While some researchers support the association of DM with severe clinical forms of acute cholecystitis $(6,11,12)$ larger studies are required to resolve this controversy.

Mean leucocyte levels were higher in DM patients despite a general belief that immune responses in diabetics are elicited in a slower and unpredictable manner. Since there was no association with the severity of the clinical form, it is considered that the number of leucocytes is linked to the chronic complications of DM as suggested by Moradi et al (13) and Coller (14), but the intimate mechanisms governing this remain partially unknown.

Intraoperative approach and outcomes. There were no statistically significant associations between the type of surgery and DM, most of the cases being performed laparoscopically. Although, the rate of conversion was higher in the diabetic group (13.2\%) vs. the non-diabetic group $(6.9 \%)$, which conformed well with the increased incidence of the severe forms of acute cholecystitis in the diabetic group (Table IV).

The ASA PS classification and CCI were significantly associated with the presence of DM $(\mathrm{P}=0.0012$ and $\mathrm{P}<0.001$, respectively; Table II). Surgery-related complications and major cardiovascular events were more common in the DM subgroup $(\mathrm{P}=0.0137$ and $\mathrm{P}=0.013$, respectively; Table IV). Healthcare-associated infections were slightly higher in the diabetic group but not statistically significant (Table IV).

\section{Discussion}

Specific physiopathological mechanisms of acute cholecystitis in diabetic patients. The present study revealed that the incidence of acute cholecystitis in diabetic patients was not sex-related with an even male to female proportion, markedly different from the general population where the female to male ratio is $4: 1$. Similar results have been reported by other authors (Kamaranos et al 55.4\%, Pagliarulo et al 53.1\%, Cho et al $46.36 \%$ and Ransohoff et al 51.12\%), but to date a plausible mechanism has not been proposed (15-18). Some studies mention a higher degree of gallbladder distension and an increased wall tension secondary to kinetic disorders caused by microangiopathy and diabetic neuropathy. Metabolic disorders and DM-related gallstone formation may play a role that is not fully elucidated. In this regard, Aune and Vatten (19) published a meta-analysis on the role of DM as a risk factor for gallbladder diseases in which unequivocal data demonstrated the role of DM in the formation of biliary calculi. The mechanisms incriminated were related to insulin resistance 
Table I. Tokyo Guideline (TG13/TG18) severity risk scale.

Grade III (severe) acute cholecystitis

Grade II (moderate) acute cholecystitis

Grade I (mild) acute cholecystitis
Acute cholecystitis with organ/system dysfunction (renal, cardiovascular, hepatic, respiratory, neurologic, hematologic)

Acute cholecystitis associated with:

i) $\mathrm{WBC}>18000 / \mathrm{mmc}$

ii) Palpable tender mass in the right upper abdominal quadrant

iii) Marked local inflammation

iv) Onset $>72 \mathrm{~h}$

Acute cholecystitis which does not meet criteria for grade II or III

WBC, white blood cells.

Table II. General data in the diabetic and non-diabetic groups.

\begin{tabular}{|c|c|c|c|}
\hline Factors & Diabetic group & Non-diabetic group & P-value \\
\hline Total no. of subjects & 46 & 287 & \\
\hline Females & $26(56.53 \%)$ & $205(71.42 \%)$ & $<0.001$ \\
\hline Males & $20(43.47 \%)$ & $82(38.58 \%)$ & \\
\hline Age $($ mean $\pm S D)(\min ; \max )$ & $64 \pm 12.1$ ( $35-88$ years $)$ & $55 \pm 16(18-91$ years $)$ & $<0.001$ \\
\hline Presentation & & & 0.646 \\
\hline Early (<72 h) & $16(34.8 \%)$ & $91(31.7 \%)$ & \\
\hline Delayed (>72 h) & $30(65.2 \%)$ & $196(68.3 \%)$ & \\
\hline $\mathrm{CCI}($ mean $\pm \mathrm{SD})$ & $2.56 \pm 1.73$ & $0.78 \pm 14$ & $<0.001$ \\
\hline $\mathrm{CCI} \geq 4$ & $14(30.43 \%)$ & $18(6.27 \%)$ & \\
\hline \multicolumn{4}{|l|}{ Diabetes } \\
\hline Uncomplicated & $24(52.2 \%)$ & & \\
\hline With complications & $22(47.8 \%)$ & & \\
\hline Arterial hypertension & $28(60.8 \%)$ & $78(27.2 \%)$ & $<0.001$ \\
\hline Ischemic cardiopathy & $21(45.6 \%)$ & $45(15.6 \%)$ & 0.0043 \\
\hline $\mathrm{ASA} \geq \mathrm{III}$ & $22(47.8 \%)$ & $68(23.69 \%)$ & 0.0012 \\
\hline \multicolumn{4}{|l|}{ ASA risk staging } \\
\hline $\mathrm{I}$ & 1 & 64 & \\
\hline II & 24 & 109 & \\
\hline III & 18 & 61 & \\
\hline IV & 4 & 5 & \\
\hline $\mathrm{V}$ & 0 & 2 & \\
\hline
\end{tabular}

Bold indicates statistical significance. ASA, American Society of Anesthesiologists Physical Status Classification; CCI, Charlston Comorbidity Index.

and disorders of lipid metabolism leading to high levels of cholesterol and triglycerides. These are frequently associated with obesity in the metabolic syndrome associated with type 2 DM (20). In other studies, increased bile saturation indexes and hypo-motility of the gallbladder induced by a decrease of cholecystokinin receptors in the gallbladder wall were observed (21-23) causing reduced smooth muscle sensibility to humoral stimulation. All these pathological mechanisms provide logical explanations for the equal sex distribution of acute cholecystitis in diabetic patients, and this particularity is more than likely the result of their complementary and cumulative effect.
Postoperative cardiovascular complications risk in diabetic patients with acute cholecystitis. The present study determined statistically significant associations between cardiovascular comorbidities (arterial hypertension, ischemic cardiopathy), ASA score and CCI used in preoperative assessment of the surgical risk.

Ischemic heart disease has been revealed to be significantly associated with DM due to the occurrence of both large vessels (accelerated atherosclerosis) and microvascular disorders. Similar studies on outcomes of cholecystectomy in diabetic patients have confirmed the interdependency between DM and acute coronary syndromes $(11,23)$. 
Table III. Preoperative assessment of the diabetic and non-diabetic groups.

\begin{tabular}{|c|c|c|c|}
\hline Factors & Diabetic group & Non-diabetic group & P-value \\
\hline $\mathrm{WBC}>18000 / \mathrm{mmc}$ & $7(15.2 \%)$ & $18(6.27 \%)$ & 0.0664 \\
\hline WBC (median \pm SD) & $11,859 \pm 5,593$ & $9,603.47 \pm 5,443.04$ & 0.018 \\
\hline Ultrasound: Double contour image & $15(32.6 \%)$ & $64(22.3 \%)$ & 0.1273 \\
\hline Creatinine $>2 \mathrm{mg} / \mathrm{ml}$ & $6(13 \%)$ & $14(4.85 \%)$ & 0.0164 \\
\hline Creatinine & $1.27 \pm 0.76$ & $1.03 \pm 0.92$ & 0.097 \\
\hline TG13/TG18 & & & 0.6562 \\
\hline Severe & $6(13.04 \%)$ & $16(5.57 \%)$ & 0.058 \\
\hline Moderate & $26(56.52 \%)$ & $182(63.4 \%)$ & \\
\hline Mild & $14(30.43 \%)$ & $89(31.01 \%)$ & \\
\hline Main duct stones & $7(15.2 \%)$ & $24(8.3 \%)$ & 0.1301 \\
\hline Angiocholitis & 1 & 3 & \\
\hline
\end{tabular}

Bold indicates statistical significance. WBC, white blood cells; TG13/TG18, Tokyo Guideline severity risk scale.

Table IV. Surgical approach and outcomes in diabetic vs. non-diabetic groups.

\begin{tabular}{|c|c|c|c|}
\hline Parameters & Diabetic group & Non-diabetic group & P-value \\
\hline Type of surgery & & & 0.1275 \\
\hline Laparoscopic cholecystectomy & $38(82.6 \%)$ & $256(89.2 \%)$ & \\
\hline Conversion & $6(13.2 \%)$ & $20(6.9 \%)$ & \\
\hline Open cholecystectomy & $2(4.34 \%)$ & $11(3.8 \%)$ & \\
\hline Severe forms & $7(15.2 \%)$ & $27(9.4 \%)$ & 0.368 \\
\hline Gangrenous & 3 & 14 & \\
\hline Piocholecystitis & 3 & 6 & \\
\hline Pericholecystitis & 1 & 3 & \\
\hline Biliary peritonitis & 0 & 4 & \\
\hline Hospital days & $6.7 \pm 5.3$ & $6.39 \pm 5.89$ & 0.695 \\
\hline Post-surgery hospitalization & $4.3 \pm 4.8$ & $3.77 \pm 3.59$ & 0.398 \\
\hline Surgery-related complications (treated conservatively) & $6(13.04 \%)$ & $12(3.83 \%)$ & 0.0137 \\
\hline Hemorrhage & 3 & 7 & \\
\hline Bile leak & 2 & 3 & \\
\hline SSI & 1 & 2 & \\
\hline Major complications & $6(13.04 \%)$ & $3(2.4 \%)$ & 0.013 \\
\hline Death & 1 (sepsis) & 2 (stroke) & \\
\hline Stroke & 0 & 2 & \\
\hline Acute myocardial infarction & 5 & 1 & \\
\hline Nosocomial infections (Clostridium, lower urinary tract infections) & $9(19.5 \%)$ & $33(11.49 \%)$ & 0.12 \\
\hline
\end{tabular}

Bold indicates statistical significance. SSI, surgical site infections.

Moreover, other systemic complications have been revealed to be associated with DM including respiratory, renal decompensation, sepsis, and systemic infections $(11,12,15,17)$. In the present study, there were no pulmonary and renal complications, and the hospital-acquired infection rates did not differ between the 2 study groups. Yet, the only death in the diabetic group was due to sepsis.

In a meta-analysis published by Łącka et al (11), mortality was revealed to be higher in diabetic patients in several studies $(24,25)$, while others found similar rates in comparison to non-diabetic patients (26-29). One explanation may be that some of the cited studies are more than 20 years old, and the development and skills in laparoscopic surgery, as well as in intensive care, would have improved the outcomes of this vulnerable category of patients. Careful preoperative preparations, meticulous intraoperative surgical techniques, and cautious postoperative care are extremely important for preventing these severe events (29). 
Impaired surgical wound healing in diabetics. In the present study, the postoperative complications related to surgery were higher in the diabetic group. These aspects can be correlated to the stiffness of the vascular wall, which leads to prolonged bleeding and tissular hypoxia, as well as impaired wound healing secondary to chronic hyperglycemia $(12,30-32)$.

Moreover, septic site infection and wound dehiscence were encountered to be more frequent in diabetic patients (28-32). In this regard, the advantages of the laparoscopic approach are extremely important, in preventing perioperative morbidity.

Severity forms and risk for conversion in diabetic patients. The present study supports the evidence according to which laparoscopic cholecystectomy remains the gold standard of treatment for diabetic patients with acute cholecystitis, considering the similar conversion rates with non-diabetic patients and no special intraoperative requirements or adjustments of techniques.

Some studies have published data revealing a higher incidence of severe cases of acute gangrenous or emphysematous cholecystitis in diabetic patients $(6,12)$, but this is not unanimously accepted. A possible explanation for the inconsistencies in study results may be related to insufficient documentation of the comorbidities and severe cases in clinical notes. The duration of DM may play a role in the development of severe cases considering that the microvascular and macrovascular complications and neuropathic changes are directly proportional to the duration of the uncontrolled hyperglycemia $(33,34)$. Chronically elevated blood sugar levels alter the immune response and render the diabetic more susceptible to infections by various mechanisms such as glycosylation of the complement proteins, inhibition of immunoglobulin-mediated opsonization of bacteria, inhibition of neutrophil migration phagocytosis, and apoptosis (35-37). Hence the pivotal role of tight glycemic control, between 100 and $140 \mathrm{mg} / \mathrm{ml}$, in the reduction of healthcare-associated infections and speedy surgical site healing (38).

Surgical management of acute cholecystitis in diabetic patients. Several studies have reported that diabetic patients are more predisposed to severe forms of acute cholecystitis, suggesting that even silent gallstones should be addressed surgically $(6,12)$. In a recent metanalysis on 40 studies regarding the clinical features and outcomes of acute cholecystitis in diabetic patients, Łącka et al (11) concluded that there is not enough evidence to recommend elective cholecystectomy as a routine in patients with DM. The present study also supports this conclusion, as there were no particular differences regarding the severity and surgical approach in diabetic vs. non-diabetic patients.

Once the gold standard for the treatment of acute cholecystitis, interval cholecystectomy is increasingly abandoned in favor of index admission laparoscopic cholecystectomy (39). This is due to studies that revealed that in trained hands early cholecystectomy is as safe as delayed surgery and that after one episode of cholecystitis the risk of developing calculi-related complications is $14 \%$ at 6 weeks, $19 \%$ at 12 weeks, and $29 \%$ at one year following discharge (39-44). Traditionally, critically ill surgical patients with acute cholecystitis should be temporized with percutaneous cholecystostomy, but there are data suggesting that in patients with organ failure, temporizing is associated with poorer outcomes and higher mortality compared to those in whom surgery is not deferred (40-42).

In conclusion, diabetic patients with acute cholecystitis are more predisposed to postoperative systemic- and surgical-related morbidity. Laparoscopic cholecystectomy is a safe procedure for diabetic patients, which can provide the best outcomes, by decreasing the risks of surgical wounds. Attentive perioperative care and good glycemic control must be provided to minimize the risk of complications.

\section{Acknowledgements}

Not applicable.

\section{Funding}

No funding was received.

\section{Availability of data and materials}

All data generated or analyzed during this study are included in this published article.

\section{Authors' contributions}

SAB, DS, AMD and ADS contributed to the conception and design of this study. CA, SAB, AMT, BS, AMD, DS and CB were responsible for the data collection and analysis. $\mathrm{SAB}$, DS, CDB, BS, IM, VA and DaS were in charge of drafting the manuscript. DaS, CDB, RIS, GCS, VA, IM revised the manuscript critically for important intellectual content. All authors read and approved the final version.

\section{Ethics approval and consent to participate}

The study was released from the formal approval of the ethical board due to its retrospective nature. All patients had previously signed an informed written consent concerning hospitalization and investigations.

\section{Patient consent for publication}

Not applicable.

\section{Competing interests}

The authors declare that they have no competing interests.

\section{References}

1. Smyth S and Heron A: Diabetes and obesity: The twin epidemics. Nat Med 12: 75-80, 2006.

2. Supe A: Asymptomatic gall stones-revisited. Trop Gastroenterol 32: 196-203, 2011.

3. Stinton LM and Shaffer EA: Epidemiology of gallbladder disease: Cholelithiasis and cancer. Gut Liver 6: 172-187, 2012.

4. Murshid KR: Asymptomatic gallstones: Should we operate? Saudi J Gastroenterol 13: 57-69, 2007.

5. Łącka M, Obłój P, Spychalski P, Łaski D, Rostkowska O, Wieszczy P and Kobiela J: Clinical presentation and outcomes of cholecystectomy for acute cholecystitis in patients with diabetes-a matched pair analysis. A pilot study. Adv Med Sci 65: 409-414, 2020. 
6. Ikard RW: Gallstones, cholecystitis and diabetes. Surg Gynecol Obstet 171: 528-532, 1990.

7. Shaw SJ, Hajnal F, Lebovitz Y, Ralls P, Bauer M, Valenzuela J and Zeidler A: Gallbladder dysfunction in diabetes mellitus. Dig Dis Sci 38: 490-496, 1993.

8. Miura F, Okamoto K, Takada T, Strasberg SM, Asbun HJ, Pitt HA, Gomi H, Solomkin JS, Schlossberg D, Han HS, et al: Tokyo guidelines 2018: Initial management of acute biliary infection and flowchart for acute cholangitis. J Hepatobiliary Pancreat Sci 25: 31-40, 2018.

9. American Society of Anesthesiologists (ASA): ASA Physical Status Classification System. https://www.asahq.org/standardsand-guidelines/asa-physical-status-classification-system. Last Amended December 13, 2020

10. Sundararajan V, Henderson T, Perry C, Muggivan A, Quan H and Ghali WA: New ICD-10 version of the Charlson comorbidity index predicted in-hospital mortality. J Clin Epidemiol 57: 1288-1294, 2004.

11. Łącka M, Spychalski P, Dobrzycka M, Rostkowska O and Kobiela J: Acute cholecystitis in patients with diabetes mellitus-systematic review. Eur J Transl Clin Med 2: 71-79, 2020

12. Shpitz B, Sigal A, Kaufman Z and Dinbar A: Acute cholecystitis in diabetic patients. Am Surg 61: 964-967, 1995.

13. Moradi S, Kerman SR, Rohani F and Salari F: Association between diabetes complications and leukocyte counts in Iranian patients. J Inflamm Res 5: 7-11, 2012.

14. Coller BS: Leukocytosis and ischemic vascular disease morbidity and mortality: Is it time to intervene? Arterioscler Thromb Vasc Biol 25: 658-670, 2005

15. Karamanos E, Sivrikoz E, Beale E, Chan L, Inaba K and Demetriades D: Effect of diabetes on outcomes in patients undergoing emergent cholecystectomy for acute cholecystitis. World J Surg 37: 2257-2264, 2003.

16. Pagliarulo M, Fornari F, Fraquelli M, Zoli M, Giangregorio F, Grigolon A, Peracchi M and Conte D: Gallstone disease and related risk factors in a large cohort of diabetic patients. Dig Liver Dis 36: 130-134, 2004.

17. Cho JY, Han HS, Yoon YS and Ahn KS: Risk factors for acute cholecystitis and a complicated clinical course in patients with symptomatic cholelithiasis. Arch Surg 145: 329-333, 2010.

18. Ransohoff DF, Miller GL, Forsythe SB and Hermann RE: Outcome of acute cholecystitis in patients with diabetes mellitus. Ann Intern Med 106: 829-832, 1987.

19. Aune D and Vatten LJ: Diabetes mellitus and the risk of gallbladder disease: A systematic review and meta-analysis of prospective studies. J Diabetes Complications 30: 368-373, 2016.

20. Méndez-Sánchez N, Chavez-Tapia NC, Motola-Kuba D, Sanchez-Lara K, Ponciano-Rodríguez G, Baptista H, Ramos MH and Uribe M: Metabolic syndrome as a risk factor for gallstone disease. World J Gastroenterol 11: 1653-1657, 2005.

21. Pazzi P, Scagliarini R, Gamberini S and Pezzoli A: Review article: Gall-bladder motor function in diabetes mellitus. Aliment Pharmacol Ther 14 (Suppl 2): S62-S65, 2000.

22. Stone BG, Gavaler S, Belle SH, Shreiner DP, Peleman RR, Sarva RP, Yingvorapant N and Van Thiel DH: Impairment of gallbladder emptying in diabetes mellitus. Gastroenterol 95: 170-176, 1988

23. Jaafar G, Hammarqvist F, Enochsson L and Sandblom G: Patient-related risk factors for postoperative infection after cholecystectomy. World J Surg 41: 2240-2244, 2017.

24. Hickman MS, Schwesinger WH and Page CP: Acute cholecystitis in the diabetic. A case-control study of outcome. Arch Surg 123 409-411, 1988

25. Abramson DJ: Diabetes mellitus and cholecystectomy. Ann Surg 145: 371-378, 1957.

26. Bodmer M, Brauchli YB, Jick SS and Meier CR: Diabetes mellitus and the risk of cholecystectomy. Dig Liver Dis 43: 742-747, 2011.
27. Al-Mulhim AR: The outcome of laparoscopic cholecystectomy in diabetic patients: A prospective study. J Laparoendosc Adv Surg Tech A 20: 417-420, 2010.

28. Bouassida M, Chtourou MF, Charrada H, Zribi S, Hamzaoui L, Mighri MM and Touinsi H: The severity grading of acute cholecystitis following the Tokyo guidelines is the most powerful predictive factor for conversion from laparoscopic cholecystectomy to open cholecystectomy. J Visc Surg 154: 239-243, 2017.

29. Paajanen H, Suuronen S, Nordstrom P, Miettinen P and Niskanen L: Laparoscopic versus open cholecystectomy in diabetic patients and postoperative outcome. Surg Endosc 25 764-770, 2011.

30. Spampinato SF, Caruso GI, De Pasquale R, Sortino MA and Merlo S: The treatment of impaired wound healing in diabetes: Looking among old drugs. Pharmaceuticals (Basel) 13: 60, 2020

31. Patel S, Srivastava S, Singh MR and Singh D: Mechanistic insight into diabetic wounds: Pathogenesis, molecular targets and treatment strategies to pace wound healing. Biomed Pharmacother 112: 108615, 2019

32. Liu CM, Chung CL, Hsu CT, Song MZ, Chen CC and Li CY: Impact of diabetes mellitus on cholecystectomy rate: A population-based follow-up study. Formos J Surg 48: 157-162, 2015.

33. Suceveanu AI, Stoian AP, Parepa I, Voinea C, Hainarosie R, Manuc D, Nitipir C, Mazilu L and Suceveanu AP: Gut microbiota patterns in obese and type 2 diabetes (T2D) patients from romanian black sea coast region. Rev Chim 69: 2260-2267, 2018.

34. Hainarosie R, Zainea V, Rusescu A, Iana RO, Ghindea T, Suceveanu AP, Stefanescu DC, Ionita IG, Pietrosanu C and Pantea Stoian A: Management of infectious complications in diabetes mellitus mellitus patients. Rom J Mil Med 122: 46-51, 2019.

35. Jafar N, Edriss $\mathrm{H}$ and Nugent K: The effect of short-term hyperglycemia on the innate immune system. Am J Med Sci 351: 201-211, 2016.

36. Casqueiro J, Casqueiro $\mathrm{J}$ and Alves $\mathrm{C}$ : Infections in patients with diabetes mellitus: A review of pathogenesis. Indian J Endocrinol Metab 16 (Suppl 1): S27-S36, 2012.

37. Xiu F, Stanojcic M, Diao L and Jeschke MG: Stress hyperglycemia, insulin treatment, and innate immune cells. Int $\mathrm{J}$ Endocrinol 2014: 486403, 2014.

38. Katsiki N, Kotsa K, Stoian AP and Mikhailidis DP: Hypoglycaemia and cardiovascular disease risk in patients with diabetes. Curr Pharm Des 26: 5637-5649, 2020.

39. Yu H, Chan EE, Lingam P, Lee J, Woon WWL, Low JK and Shelat VG: Index admission laparoscopic cholecystectomy for acute cholecystitis restores gastrointestinal quality of life index (GIQLI) score. Ann Hepatobiliary Pancreat Surg 22: 58-65, 2018.

40. Ozkardes AB, Tokac M, Dumlu EG, Bozkurt B, Ciftçi AB Yetişir F and Kılıç M: Early versus delayed laparoscopic cholecystectomy for acute cholecystitis: A prospective, randomized study. Int Surg 99: 56-61, 2014.

41. Vaccari S, Cervellera M, Lauro A, Palazzini G, Cirocchi R, Gjata A, Dibra A, Ussia A, Brighi M, Isaj E, et al: Laparoscopic cholecystectomy: Which predicting factors of conversion? Two Italian center's studies. Minerva Chir 75: 141-152, 2020.

42. Khan MN, Nordon I, Ghauri AS, Ranaboldo C and Carty N: Urgent cholecystectomy for acute cholecystitis in a district general hospital-is it feasible? Ann R Coll Surg Engl 91: 30-34, 2009.

43. de Mestral C, Rotstein OD, Laupacis A, Hoch JS, Zagorski B and Nathens AB: A population-based analysis of the clinical course of 10,304 patients with acute cholecystitis, discharged without cholecystectomy. J Trauma Acute Care Surg 74: 26-30, 2013.

44. Mou D, Tesfasilassie T, Hirji S and Ashley SW: Advances in the management of acute cholecystitis. Ann Gastroenterol Surg 3: 247-253, 2019. 